\title{
Tilt and caval penetration among permanent and retrievable inferior vena cava filters of similar design
}

\author{
Joseph T Marion' ${ }^{1}$, Edwin A Takahashi ${ }^{1}$, Newton B Neidert ${ }^{1,2}$, Melissa J Neisen ${ }^{1,2}$, William S Harmsen ${ }^{1,3}$ and Sanjay Misra ${ }^{1,2 *}$ \\ ${ }^{1}$ Department of Radiology, Mayo Clinic, Rochester, Minnesota, USA \\ ${ }^{2}$ Division of Vascular and Interventional Radiology, USA \\ ${ }^{3}$ Department of Clinical Statistics, Mayo Clinic, Rochester, Minnesota, USA
}

\begin{abstract}
Purpose: The goals of this research were to compare tilt and caval penetration rates of the Günther Tulip (Cook Medical, Bloomington, IN) and Greenfield (Boston Scientific, Marlborough, MA) inferior vena cava (IVC) filters, and assess the difficulty of Tulip retrieval based on filter tilt, dwell time and caval wall penetration.

Methods: Institutional review board approval was granted for this study, IRB \#18-003517. Informed consent was waived by the institutional review board. This retrospective study reviewed Greenfield filter placement $(n=26)$ and Tulip filter $(n=203)$ removal. The electronic medical record was reviewed and a single author determined filter angle and caval penetration on the most recent available CT or catheter venogram. Filters removed with a snare were analyzed as routine removal and filters requiring additional devices or procedures were placed in a difficult removal group.
\end{abstract}

Results: Greenfield filters had longer dwell time with a mean \pm standard deviation of $811.3 \pm 1398.1$ days compared to $183.8 \pm 262.1$ days for Tulip filters ( $\mathrm{p}=0.845$ ). Filter tilt angle was not significantly different between the filter types $7.2 \pm 4.7$ for Greenfield filters and $5.5 \pm 4.8$ degrees for Tulip filters ( $p=0.09$ ). Four (15.4\%) Greenfield filters and $47(23.2 \%)$ Tulip filters penetrated the caval wall $>3 \mathrm{~mm}(\mathrm{P}=0.37)$. Of the Tulip filters, those in the difficult removal group had a mean tilt of $7.6 \pm 6.5$ degrees compared to $4.6 \pm 3.6$ degrees in the routine removal group $(p=0.0057)$.

Conclusion: Greenfield IVC filters with longer dwell times demonstrate similar degrees of filter tilt and caval penetration as Tulip filters. A mean tilt of $7.6 \pm 6.5$ degrees indicates a filter which may require additional or alternative techniques for removal.

\section{Introduction}

Inferior vena cava (IVC) filters are commonly placed in patients at risk for pulmonary embolism (PE) or who have PE and a contraindication to anticoagulation, have failed anticoagulation, or have had a complication related to anticoagulation [1]. Over the past several decades, there have been numerous iterations to the IVC filter design and conically-shaped IVC filters are currently the most commonly used type of filter [2]. Permanent filters have largely been replaced by retrievable filters due to increased risk of lower extremity thrombosis associated with prolonged permanent filter dwell time $[1,3,4]$.

Filter-related complications include caval wall penetration, IVC thrombosis, and in some cases, retrievable filters cannot be safely removed due to hook contact with the caval wall or strut penetration through the cava [1,5-7]. These issues tend to be magnified by the degree of filter tilt and duration of dwell time [8]. Although similar potential complications exist between permanent and retrievable filters, permanent filters are associated with fewer device related complications $[7,9]$.

The purpose of this study was to compare IVC filter tilt and caval penetration rates of the similar, conically shaped permanent Greenfield (Boston Scientific, Marlborough, MA) filter and the retrievable Günther Tulip (Cook Medical, Bloomington, IN) filter, as well as evaluate the impact of tilt and penetration on retrievability of Tulip filters.

\section{Methods}

Institutional review board approval was granted for this single institution, retrospective review, and the study was compliant with the Health Insurance Portability and Accountability Act. Informed consent was waived by the institutional review board.

\section{Patients}

A keyword search of the institutional radiology database identified 225 patients who underwent Tulip filter placement and removal, as well as 75 patients who underwent Greenfield filter placement between January 1, 2000 and August 31, 2017. Patients with multiple filters, unavailable follow-up imaging, suprarenal filters or variant venous anatomy were excluded from analysis. The electronic medical record was reviewed for patient characteristics, comorbidities, filter indication, and procedural details. Patient characteristics listed by filter type are recorded in Table 1 .

*Correspondence to: Misra S, MD, FSIR FAHA, Professor of Radiology, Mayo Clinic, Department of Radiology, 200 First Street SW, Rochester, MN 55905, USA, Tel: 507-255-7208; Fax: 507-255-7872; E-mail: misra.sanjay@mayo.edu

Received: November 04, 2019; Accepted: November 15, 2019; Published: November 18, 2019 
Table 1. Patient characteristics by filter type

\begin{tabular}{|l|c|c|}
\hline Characteristic & Greenfield Filters & Tulip Filters \\
\hline Total, $\mathrm{n}$ & 26 & 203 \\
\hline Age, years, mean (SD) & $67.7(9.6)$ & $55.0(17.2)$ \\
\hline Sex, $\mathrm{n}(\%)$ & & \\
\hline Male & $17(65.4)$ & $117(57.6)$ \\
\hline Female & $9(34.6)$ & $86(42.4)$ \\
\hline Comorbidities, $\mathrm{n}(\%)$ & $9(34.6)$ & $62(30.5)$ \\
\hline Hypertension & $4(15.4)$ & $51(25.1)$ \\
\hline Hyperlipidemia & $2(7.7)$ & $28(13.8)$ \\
\hline Diabetes & $1(3.8)$ & $15(7.4)$ \\
\hline Chronic Kidney Disease & $2(7.7)$ & $35(17.2)$ \\
\hline Obesity & $4(15.4)$ & $28(13.8)$ \\
\hline Inflammatory/Autoimmune & $1(3.8)$ & $26(12.8)$ \\
\hline Obstructive Sleep Apnea & $2(7.7)$ & $16(7.9)$ \\
\hline Smoking Tobacco Use & $5(19.2)$ & $22(10.8)$ \\
\hline $\begin{array}{l}\text { Vascular Disease (Peripheral arterial } \\
\text { disease, coronary artery disease, abdominal } \\
\text { aortic aneurysm) }\end{array}$ & & \\
\hline
\end{tabular}

\section{Filter placement procedure}

IVC filters were placed by either the transfemoral or transjugular approach based on operator preference. A flush catheter was advanced into the infrarenal IVC, and a venogram was performed to delineate the location of the renal veins. The filter was then advanced into the infrarenal IVC and deployed. Post-placement venograms were not routinely performed.

\section{Filter removal procedure}

Routine filter retrieval was defined as filters that were retrieved without additional, unplanned procedures. From a transjugular approach, a flush catheter was advanced below the level of the filter and a venogram performed to assess for thrombus within the filter. A retrieval set was advanced into the IVC and a gooseneck snare used to capture the filter hook. The sheath was then telescoped over the filter which was removed in entirety as confirmed by physical inspection. Any deviation from or addition to this procedure was considered a difficult retrieval.

\section{Image interpretation}

Retrieval venogram filter tilt was measured with respect to the caval wall using a dedicated Digital Imaging and Communications in Medicine (DICOM) workstation. Filter tilt was also measured on coronal maximum intensity projection (MIP) reformats of the patient's most recent computed tomography (CT) imaging study that included the filter using TeraRecon software (Aquarius iNtuition, Foster City, CA). These CTs included a variety of study types obtained for numerous indications. For patients who had both CT and venogram tilt measurements, the latest measurement was used for analysis. Caval penetration was reviewed and graded based on the ACR-SIR-SPR Practice Parameters definition of filter strut or anchor penetration [10].

\section{Statistical analysis}

Statistical analyses were performed with JMP software (JMP Pro version 13.0.0; SAS, Cary, NC). The relationship between the continuous variables dwell time and filter angle were compared to categorical variables filter type, comorbidities, placement approach, caval wall penetration and filter removal using the Wilcox rank sum test. The relationship between the listed categorical variables was determined with Pearson's $\chi^{2}$ test. Statistical significance was achieved at a $P$ value of less than 0.05 .

\section{Results}

\section{Filter indication}

A total of 26 Greenfield and 203 Tulip filters were analyzed. The most common indication for filter placement was $\mathrm{PE}$ or deep vein thrombosis (DVT) with contraindications to anticoagulation (39.5\%), followed by trauma $(30.3 \%)$, preoperative prophylaxis $(15.6 \%)$, and oncologic related prophylaxis (14.7\%) (Table 2). Compared to Greenfield filters, Tulip filters were placed more often for PE prophylaxis in the setting of trauma $(\mathrm{p}=0.004)$ and in younger patients $(\mathrm{p}<0.001)$.

\section{Filter tilt}

All analyzed filters were placed in the infrarenal IVC. In total, 122 (53\%) filters were placed from a femoral approach and had a mean filter tilt of $6.2 \pm 5.1$ degrees, while 107 (47\%) filters were placed from a jugular approach had a mean filter tilt of $5.0 \pm 4.8$ degrees $(p=0.028)$. Greenfield filters were more likely to be placed from a femoral approach (88.9\% versus $50.5 \%$ for Tulip, $\mathrm{p}=0.001$ ).

Greenfield filters had a longer mean dwell time compared to Tulip filters, although the difference was not statistically significant $(811.3$ \pm 1398.1 days versus $183.8 \pm 262.1$ days respectively, $\mathrm{p}=0.845)$. No statistically significant difference in filter tilt was observed $(7.2 \pm 4.7$ degrees for Greenfield versus $5.5 \pm 4.8$ degrees for Tulip, $\mathrm{p}=0.091$ ).

\section{Caval wall penetration}

Four (15.4\%) Greenfield filters and 47 (23.2\%) Tulip filters demonstrated $>3 \mathrm{~mm}$ strut penetration beyond the caval wall $(\mathrm{p}=$ $0.37)$. Filter tilt was not significantly associated with a higher incidence of caval penetration $(\mathrm{P}=0.353)$. Among filters with caval penetration $>3$ $\mathrm{mm}$, Greenfield filters had significantly longer dwell time $(\mathrm{P}=0.002)$.

\section{Tulip filter retrieval}

Factors affecting routine removal and difficult filter retrieval are listed in Table 3. All 203 Tulip filters were removed (100\%). One hundred forty-three $(70.4 \%)$ were routine retrievals without complication, and 60 (29.6\%) were removed with additional techniques or multiple attempts. Dwell time of routinely retrieved filters (147.6 \pm 155.7 days) was significantly shorter than those filters removed with additional techniques $(281.5 \pm 421.9$ days $), p=0.013$. The filter tilt for routine removal was $4.6 \pm 0.4$ degrees, compared to $7.6 \pm 0.7$ degrees for filters requiring additional procedures, which was statistically significant $(\mathrm{p}=0.006)$. The difference in tilt between routine and difficult retrievals among filters placed from the transjugular approach was not significant $(\mathrm{p}=0.114)$. In a multivariable model including both "approach" and "angle" to predict "difficult retrieval," a one degree increase in filter angle was associated with approximately a 14\% increased odds of difficult removal (HR=1.14, 95\% CI 1.06-1.21; $\mathrm{p}<0.001)$.

Among 101 filters placed from a femoral approach, the 29 (28.7\%) filters in the difficult retrieval group had an average tilt of $8.7 \pm 7.3$ degrees compared to $4.8 \pm 3.3$ degrees among those in the routine removal group. This difference was not significantly different in the same multivariable model mentioned above $(\mathrm{p}=0.53)$.

Hook contact with the caval wall was associated with a greater proportion of difficult filter retrievals. Out of 37 filters contacting the caval wall, $20(54.0 \%)$ were difficult to retrieve, compared to 156 filters not contacting the caval wall, 30 (19.2\%) were difficult to retrieve $(\mathrm{p}<0.001)$. In addition, 10 of 10 filters with hook penetration through the caval wall were associated with higher rate of difficult retrieval compared to filter hooks contacting the caval wall ( $\mathrm{p}=0.008)$. 
Table 2. Comparison of Greenfield and Tulip placement approach, filter tilt and caval wall penetration

\begin{tabular}{|c|c|c|c|}
\hline Variable & Greenfield Filters & Tulip Filters & P value \\
\hline \multicolumn{4}{|l|}{ Indication, $\mathbf{n}(\%)$} \\
\hline $\begin{array}{l}\text { PE or DVT with contraindication to } \\
\text { anticoagulation }\end{array}$ & $13(50.0)$ & $76(37.4)$ & \\
\hline Trauma & $1(3.8)$ & $63(31.0)$ & \\
\hline Preoperative prophylaxis & $4(15.4)$ & $33(16.3)$ & \\
\hline Oncologic related prophylaxis & $8(30.8)$ & $31(15.3)$ & \\
\hline Dwell Time, days (SD) & $811.3(1398.1)$ & $183.8(262.1)$ & 0.85 \\
\hline \multicolumn{4}{|l|}{ Placement Approach, n (\%) } \\
\hline Jugular & $5(19.2)$ & $102(50.2)$ & \\
\hline Femoral & $21(80.8)$ & $101(49.8)$ & \\
\hline \multicolumn{4}{|l|}{ Filter Tilt, degrees (SD) } \\
\hline All placement approaches & $7.2(4.7)$ & $5.5(4.8)$ & 0.09 \\
\hline Jugular approach & $2.8(2.5)$ & $5.1(4.5)$ & 0.48 \\
\hline Femoral approach & $7.7(4.7)$ & $6.0(5.1)$ & 0.09 \\
\hline Caval Wall Penetration >3 mm, n (\%) & $4(15.4)$ & $47(23.2)$ & \\
\hline Filter tilt, degrees (SD) & $4.4(2.4)$ & $7.8(6.4)$ & 0.35 \\
\hline Dwell time, days (SD) & $2566.3(2530.6)$ & $218.8(288.4)$ & 0.002 \\
\hline
\end{tabular}

Table 3. Tilt and dwell time characteristics of retrieved Tulip filters

\begin{tabular}{|c|c|c|c|}
\hline Variable & Routine Removal & Difficult Removal \\
\hline Tulip filter removal, $\mathrm{n}(\%)$ & $143(70.4)$ & $60(29.6)$ & $7.6(6.5)$ \\
\hline Filter tilt, degrees (SD) & $4.6(3.6)$ & 0.006 \\
\hline Dwell time, days (SD) & $147.6(155.8)$ & $281.5(421.9)$ \\
\hline
\end{tabular}

\section{Discussion}

In this study, Tulip and Greenfield filters demonstrated similar filter tilt and caval wall penetration rates despite Greenfield filters having longer dwell times. Additionally, relatively small filter tilt angles were found to be associated with significantly more difficult Tulip filter retrieval.

The Tulip and Greenfield filters were chosen based on their similar conical design and frequency of implantation. Due to the changing patterns of filter choice among interventionalists at our institution, all Greenfield filters analyzed in this study were placed prior to the Tulip filters. Additionally, only Tulip filters placed in the past seven years at our institution were analyzed to represent the latest trends and techniques.

Filter tilt and caval wall penetration are common issues of conically-shaped IVC filters, including the permanent Greenfield and retrievable Tulip filters $[2,5-9,11]$. Filter tilt and penetration have been recognized to increase the chance of difficult or failed filter removal leading to patient morbidity [11,12]. Longer Tulip filter dwell times increase the risk for filter tilt as well as the risk of caval wall penetration $[6,8]$. Additionally, a tilted filter can change the flow pattern of blood and lead to undesired vessel remodeling [13].

In this study, Greenfield filters had a longer dwell time of 811.3 days compared to 183.8 days for Tulip filters $(p=0.85)$. This is expected given the indication for both filters. However, Greenfield filters did not demonstrate greater tilt than Tulip filters. While longer dwell time and greater tilt may be seen in a larger sample of Greenfield filters, this finding does suggest the subtle differences in design between the filter types allow Greenfield filters to resist progressive tilting.

Both Greenfield and Tulip filters placed from the transfemoral approach had greater tilt compared to the transjugular approach. Furthermore, the degree of tilt was positively correlated with increased filter retrieval difficulty. Therefore, the transjugular approach may be associated with better rates of routine filter retrieval. This is counter to the study by Sag et al, which demonstrated greater tilt associated with transjugular insertion [11]. One major difference between the Sag et.al. study and the current study is the filter dwell time. The dwell time of Tulip filters was 62.6 days compared to 183.8 days in the current study.

In the literature, reported rates of Tulip filter caval wall penetration involving at least one filter strut range from $17 \%$ to $86 \%$. Additionally, Tulip filters have demonstrated progression of penetration with time $[6,8]$. Durack et al reported a caval wall penetration rate of $86 \%$ for Tulip filters at a mean follow-up time of 188 days [8]. The observed caval wall penetration rate of Tulip filters was not statistically different from that of Greenfield filters in the current study, which suggests that Greenfield filters are less prone to progressive caval wall penetration given the longer duration of implantation.

This study analyzed the use of additional procedures or techniques used to successfully retrieve Tulip filters. Although the majority of Tulip filters were retrieved uneventfully with a snare, several required additional devices and procedures to remove. Additional devices included larger sheath, forceps and angioplasty balloons, and adjunctive procedures such as the "loop-and-snare" technique in which a wire is snared through the filter struts, redirecting the filter tip with a second catheter [14]. These additional devices and procedures add cost, increase the risk for complications, and should not be considered as routine. In this study, additional devices and procedures were employed among Tulip filters with a mean filter tilt of 7.6 degrees. Multivariate analysis demonstrated a $14 \%$ increased odds of difficult removal for each additional degree of tilt. This finding suggests a need to reevaluate the current definition of significant filter tilt, defined as $\geq 15$ degrees [10], which was established using clot trapping data and experience of the Greenfield filter $[15,16]$. While 15 degrees may correlate with poor thrombus trapping ability of both permanent and retrievable conical filters, a smaller degree of tilt may be associated with difficult filter 
retrieval. Additionally, hook contact and penetration through the caval wall are significantly associated with difficult retrieval. Preprocedure calculation of filter tilt angle and identification of hook contact with the caval wall can aid in procedure planning.

The present study is limited by its retrospective design. The manner in which patients were included in the study may have introduced selection bias by including patients who had undergone filter removal or had follow-up imaging and excluding patients with Tulip filters that had not been removed. Patients with indwelling Tulip filters who may have had a longer dwell time and cross-sectional imaging were not included and as such, the observed rates of filter tilt and caval wall penetration may not represent the true rates. However, this was necessary to assess the characteristics of filter retrieval. This study analyzed two conical filters. Several other conical filters are in clinical use and the results herein may not be applicable to other filters.

In conclusion, permanent Greenfield IVC filters with longer dwell times demonstrate similar degrees of filter tilt and rates of caval penetration as retrievable Tulip IVC filters. This suggests superior durability of Greenfield filters. Also, a relatively small filter tilt of 7.6 degrees was associated with difficult Tulip filter retrieval, which indicates a need to reevaluate the current definition of significant tilt.

\section{Main points}

1. IVC filter tilt and caval wall penetration are associated with difficult filter retrieval.

2. Although Greenfield and Tulip filters have a similar design, Greenfield filters demonstrate a lesser degree of tilt and caval wall penetration with time.

3. Tulip filters with a relatively small tilt angle are associated with difficult retrieval.

\section{Disclosures}

SM has NIH funding from HL098967 and DK107870.

\section{References}

1. Sarosiek S, Crowther M, Sloan JM (2013) Indications, complications, and management of inferior vena cava filters: the experience in 952 patients at an academic hospital with a level I trauma center. JAMA Intern Med 173: 513-517.
2. Jia Z, Wu A, Tam M, Spain J, McKinney JM, et al. (2015) Caval Penetration by Inferior Vena Cava Filters: A Systematic Literature Review of Clinical Significance and Management. Circulation 132: 944-952.

3. Decousus H, Leizorovicz A, Parent F (1998) A clinical trial of vena caval filters in the prevention of pulmonary embolism in patients with proximal deep-vein thrombosis. Prevention du Risque d'Embolie Pulmonaire par Interruption Cave Study Group. $N$ Engl J Med 338: 409-415.

4. Group PS (2005) Eight-year follow-up of patients with permanent vena cava filters in the prevention of pulmonary embolism: the PREPIC (Prevention du Risque d'Embolie Pulmonaire par Interruption Cave) randomized study. Circulation 112: 416-422.

5. McLoney ED, Krishnasamy VP, Castle JC, Yang X, Guy G (2013) Complications of Celect, Gunther tulip, and Greenfield inferior vena cava filters on CT follow-up: a single-institution experience. $J$ Vasc Interv Radiol 24: 1723-1729.

6. Olorunsola OG, Kohi MP, Fidelman N (2013) Caval penetration by retrievable inferior vena cava filters: a retrospective comparison of Option and Gunther Tulip filters. $J$ Vasc Interv Radiol 24: 566-571.

7. Desai TR, Morcos OC, Lind BB (2014) Complications of indwelling retrievable versus permanent inferior vena cava filters. J Vasc Surg Venous Lymphat Disord 2: 166-173.

8. Durack JC, Westphalen AC, Kekulawela S (2012) Perforation of the IVC: rule rather than exception after longer indwelling times for the Gunther Tulip and Celect retrievable filters. Cardiovasc Intervent Radiol 35: 299-308.

9. Andreoli JM, Lewandowski RJ, Vogelzang RL, Ryu RK (2014) Comparison of complication rates associated with permanent and retrievable inferior vena cava filters: a review of the MAUDE database. $J$ Vasc Interv Radiol 25: 1181-1185.

10. ACR-SIR-SPR Practice Parameter for The Performance Of Inferior Vena Cava (Ivc) Filter Placement For The Prevention Of Pulmonary Embolism, 2016.

11. Sag AA, Stavas JM, Burke CT, Dixon RG, Marquess JS, et al. (2008) Analysis of tilt of the Gunther Tulip filter. J Vasc Interv Radiol 19: 669-676.

12. Marquess JS, Burke CT, Beecham AH (2008) Factors associated with failed retrieval of the Gunther Tulip inferior vena cava filter. J Vasc Interv Radiol 19: 1321-1327.

13. Singer MA, Wang SL (2011) Modeling blood flow in a tilted inferior vena cava filter: does tilt adversely affect hemodynamics. $J$ Vasc Interv Radiol 22: 229-235.

14. Iliescu B, Haskal ZJ (2012) Advanced techniques for removal of retrievable inferior vena cava filters. Cardiovasc Intervent Radiol 35: 741-750.

15. Katsamouris AA, Waltman AC, Delichatsios MA, Athanasoulis CA (1988) Inferior vena cava filters: in vitro comparison of clot trapping and flow dynamics. Radiology 166: 361-366.

16. Rogers FB, Strindberg G, Shackford SR (1998) Five-year follow-up of prophylactic vena cava filters in high-risk trauma patients. Arch Surg 133: 406-411.

Copyright: (C2019 Marion JT. This is an open-access article distributed under the terms of the Creative Commons Attribution License, which permits unrestricted use, distribution, and reproduction in any medium, provided the original author and source are credited. 